\title{
Leader Possible Selves: A New Motivational Construct to Consider in College Student Leader Development?
}

\author{
Valerie I. Sessa \\ Montclair State University \\ Jennifer D. Bragger \\ Montclair State University \\ Nicole Alonso \\ University of Houston \\ Quinn E. Knudsen \\ Montclair State University \\ Margaret J. Toich \\ Montclair State University
}

\begin{abstract}
Using Avolio and Vogelgesang's (2011) Leader Possible Selves (LPSS) model as a guide, this research further defines LPS, explores predictors of LPS in college students, and determines if LPS is associated with development of the leader self-concept via participation in college leadership development opportunities. We tested hypotheses derived from the model using three secondary databases. Previous leadership experience and psycho-social development predicted LPS in all three studies. LPS was associated with leadership development in all three studies. This research suggests that LPS should be included in research geared towards understanding leadership development.
\end{abstract}

\section{INTRODUCTION}

Theorists have begun to speculate that leader possible selves (LPSs) are a critical part of leader development because they are relevant to an individual's understanding of oneself and one's experience as a leader; as such, they provide a structure around which relevant knowledge can be organized and provide the motivation to seek out developmental situations (Avolio \& Vogelgesang 2011; Ibarra, Snook, \& Ramo, 2008). However, little research has been conducted regarding what constitutes a LPS, what aids in the formation of a LPS, and whether holding a LPS is associated with subsequent leader development. Recent work emphasizing the importance of paying attention to leader development earlier in life (Murphy \& Johnson, 2011), particularly at the adolescent stage of identity development (Avolio \& Vogelgesang, 2011) and that identity formation is most dynamic during the age of traditional college aged students (see Dunkel \& Anthis, 2001) present a strong case for investigating the development of a LPS 
and the influence of LPS on leadership experiences in college students. Using Avolio \& Vogelgesang's (2011) model as a guide, we further define the LPS and analyze data from secondary databases to explore predictors of LPS in college students and to determine if LPS is associated with further development of the leader self-concept via the decision to participate in college leadership development opportunities.

\section{Leader Possible Selves}

While the actual self refers to a person's representation of who they already are, possible selves represent individuals' ideas of what they might become, what they would like to become, and what they are afraid of becoming (Marcus \& Nurius, 1986). Possible selves can be viewed as cognitive manifestations of enduring goals, motives, and fears, and are powerful incentives that motivate action in the pursuit and acquisition of those goals (Oyserman, Bybee, \& Terry, 2006). Theories such as selfdiscrepancy theory where the discrepancy between actual self and possible self provide direction and impetus for action, change, and development towards becoming that possible self (Higgins, 1987), or theories suggesting a self-regulatory mechanism that guides and regulates behavior (see Lord, Diefendorff, Schmidt, \& Hall, 2010) suggest ways in which individuals' possible selves may direct and motivate behavior.

Possible selves can include general descriptors, physical descriptors, life style possibilities, general abilities, occupational possibilities, and how you are viewed by others (Marcus \& Nurius, 1986). One domain in which a possible self can emerge is leadership (Avolio \& Vogelgesang, 2011). Components of a LPS might include the ability to see oneself as a leader (referred to as availability, Norman \& Aron, 2002), the desire (or not) to be a leader (referred to as accessibility, Norman \& Aron, 2002), the belief that one can become a leader (referred to as perceived control, Norman \& Aron, 2002), and the choice of the type of leader to be. However, while discussed in the literature, this construct has never been explicitly defined, measured, or researched. In this paper, we explore LPS in terms of whether students believe that they can become a leader (perceived control) and the desire (or not) to be a leader after college (accessibility).

\section{Perceived Control}

Perceived control deals with whether a student believes that he or she can become a leader. In this dimension, relevant questions might be: Do students believe that leadership is a trait or characteristic that a person possesses (or not)? Or do they believe that leadership is a role, process, or task that they can develop? If students believe that leadership is a characteristic or trait possessed (or not) by a person, they would not consider becoming a leader as a possible self; they would either already consider themselves as a leader or they would not think it was possible to develop into one. Since their belief is that leadership is something they have or they do not, it would not activate any motivation to become a leader. If students see leadership as a role, process, or task that can be developed, however, then a LPS has the possibility of becoming activated.

\section{Accessibility}

Accessibility deals with whether a student wants to be a leader (or not). Even if they believe that they could possibly become a leader, they may not be interested in becoming a leader in the future. In this dimension, relevant questions might be: Do students have a goal to be a leader in the future (post college)? Or even to develop his or herself as a leader? If a student does not have the goal of becoming a leader then a LPS would not currently exist. That's not to say that goals of becoming a leader couldn't develop in the future. But if students do not want to be leaders, they are not going to spend mental energy creating a LPS. If students do have the goal of becoming a leader, it is likely that they have at least an idea or rudimentary plan on how they are going to become a leader.

\section{Antecedents to the LPS}

Individuals are free to create a variety of possible selves, but they will only create them if these categories of self are salient within their particular sociocultural and historical context, from the media, 
and from their immediate social experiences. Possible selves are based on one's own values, ideals, and aspirations. They also contain an important social component in that values, ideals and aspirations are also shaped by social contexts (Oyserman \& Fryberg, 2006). Thus, possible selves are socially determined and constrained by one's environment and experiences (Markus \& Nurius, 1986), and from the representations of people individuals perceive as similar to themselves in their environment and in the media. Frazier and Hooker (2006), in their program of research, examine how a person's immediate experiences (such as their health), interpersonal contexts (such as family and close friends), social norms and social forces (such as age or stage of life), and culture (such as global culture) all impact possible selves.

Drawing on the idea of possible selves, Avolio \& Vogelgesang (2011) developed a model of leader identity emergence and considered the factors that influence whether and how a LPS emerges and how it impacts that identity. In this section, we outline the factors that they speculate impact the development of a LPS as well as add an additional factor that the literature suggests may be important to derive our hypotheses.

\section{Genetic Factors Associated with Leader Possible Selves}

Although the possible selves literature does not suggest a relationship between genetics and possible selves, leadership research demonstrates a connection between variables such as intelligence, cognitive ability, and personality with leader emergence, effectiveness and styles (see Arvey, Wang, Song, \& Li, 2014 for a review). Thus, Avolio and Vogelgesang (2011) hypothesize a relationship between those genetic factors and LPS suggesting that those factors may influence individuals' grasp and interpretation of their sociocultural context, which may influence whether or not individuals seek out environments, opportunities, and people that effect the development of a LPS.

Twin methodology studies examining the heritability of leader emergence find an estimation of 24$31 \%$ variance in leader emergence that could be accounted for by genetic components (Arvey, et al., 2014, DeNeve et. al., 2013). However, using meta-analysis to look at the relationships between genetics and leader emergence, Ilies, Gerhardt \& Le (2004) found only $17 \%$ of the variance accounted for by genetics as mediated by the "big five" personality variables and intelligence, suggesting that there are other variables that may also mediate the genetics-leadership emergence linkage. In addition, intelligence has shown to predict leadership role occupancy across an individual's life (Daly \& O'Reilly, 2015), and research shows intelligence has a strong genetic component. (Judge Colbert, \& Ilies, 2004; Mumford, Campion, \& Morgeson, 2007), suggesting another possible link.

In this study, we include academic achievement (GPA) as a proxy for intelligence as research demonstrates that performance on intelligence tests is correlated with school achievement (see Kranzler, Benson, \& Floyd, 2015). Although GPA has demonstrated strong correlations with other measures of cognitive ability, it has been found to be a moderately contaminated measure of intelligence due to its relationship with motivation and conscientiousness (Ployhart \& Holtz, 2008). Previous research also has demonstrated a relationship between SAT scores and general cognitive ability (Frey \& Detterman, 2004). However, multiple universities in this study do not collect SAT scores as a criterion for admission. This leads to the following hypothesis:

\section{H1: Level of intelligence (as measured by GPA) is positively related to scoring higher on a LPS scale.}

\section{Situational Factors Associated with Leader Possible Selves}

Although traits such as intelligence and personality are considered global and enduring, when and how they are activated also depends on situational factors. Avolio \& Vogelgesang (2011), in line with Markus \& Nurius, (1986) also include the situational factors of family background and prior leadership experiences in their model of factors influencing the development of a LPS, as these factors are part of the context that determine which selves are deemed possible by the individual. 


\section{Family Background}

Home environments and child-rearing practices are significant factors in shaping children and adolescent lives. There is a vast body of literature that emphasizes the role of parents in children's early socialization and development. Parents are seen as baring responsibility for nurturing their children and carefully grooming them into functioning adults who contribute to society (Maccoby, 2000). Among factors related to parenting and child-rearing, socioeconomic status (SES) generates much attention. Parents of high SES are able to provide their children with a wider range of experiences, material resources, and social interactions that many low SES families do not have access to, resulting in differential outcomes for children (Bradley \& Corwyn, 2002). For example, studies have established a link between parent's SES and child rearing practices (Yunus \& Dahlin, 2013) and between SES and educational outcomes of children (Kan \& Tsai, 2005; Yunus \& Dhalan, 2013). In traditional college aged students, SES is associated with expectations for oneself in a future job (work possible self, Pisarik \& Shoffner, 2009) and the likelihood of participating in positional leadership positions while in college (Soria, Hussein, \& Vue, 2014). These studies suggest that family SES may influence the environment and opportunities that individuals are exposed to, which in turn could influence the emergence of an LPS in college students. This leads to the following hypothesis:

\section{H2a: Family SES is positively related to scoring higher on a LPS scale.}

\section{Mentors and Role Models}

The construction of possible selves also takes place in other significant relationships, such as with peers and role models (see Kerpelman, 2001) and within relationships with other significant adults (see Carroll 2014); both might exist within and outside of the family. In fact, research suggests that adolescents may regulate their behaviors to fit in with others' behaviors and based on others' expectations of them, rather than regulating their behaviors to consistently work toward a particular internally defined goal (e.g., Kiesner, Cadinu, Poulin, \& Bucci, 2002; Rubin, Bukowski, \& Parker, 1998). Mentors and role models may influence the development of possible selves in two ways. First, individuals may listen to the encouragement, suggestions, and feedback of important others. Carroll (2014) found that college students were more likely to embrace commitment to a new possible self when a career advisor validated this possible self. Second, college students may learn vicariously through observing influential others to determine what might be possible for them (see Ibarra, Snook \& Ramos, 2008). Research suggests that mentors and role models do play a role on college student leader identity development (see Komives, Owen, Longerbeam, Mainella, \& Osteen, 2005) and college student leader competency development (see Dugan \& Komives 2010). These studies suggest that mentors and role models may also influence the environment and opportunities that developing individuals are exposed to, which in turn could influence the emergence of a LSP.

\section{H2b: Having mentors and role models is positively related to scoring higher on a LPS scale.}

\section{Prior Experiences}

In addition to constructing possible selves within and through relationships with influential others, individuals can also construct possible selves based on their prior experiences (Markus \& Nurius, 1986). Research in identity development and leadership development has focused on previous experience and triggering events (see Sessa, 2017). First, students can have held leader positions or participated in leader development prior to college. College student precollege leadership capacity, knowledge, and success regularly emerge as significant predictors of taking on leader positional roles in college and beyond (Arvey, Zhang, Avolio, \& Kruger, 2007; Dugan \& Komives, 2006; Dugan, Garland, Jacoby, \& Gasiorski, 2008). In addition to holding positional leader roles or participating in leadership development before college, students may also experience some sort of triggering event that encourages them to develop an LPS. Triggering events (also referred to as turning points, epiphanies, defining moments, or crucibles) are points of disequilibrium and heightened self-awareness that can lead individuals to challenge their basic 
beliefs and assumptions (Avolio \& Luthans, 2006, pp. 335) and may include unexpected opportunities, challenges, or losses. Triggering events have been linked to the development of new possible selves in racial identity (Neville \& Cross, 2017). They have also been linked to leader identity development (Toor \& Ofori, 2008) and to leader development (see Shamir \& Eilam, 2005). Triggering events related to leadership may challenge an individual's assumptions about him or herself as a leader thus leading to participation in leadership development or taking on a leadership role. Together, these studies suggest that pre-college leadership experiences and triggering events could influence the emergence of an LPS in college students.

H2c: Prior leadership experiences and triggering events are positively related to scoring higher on a LPS scale.

\section{Psychosocial Development}

Possible selves are also grounded within a developmental context. Here we consider psychosocial development, which relates to a person's psychological development in, and interaction with, the social environment. Identity researchers suggest that identity formation is most dynamic between the ages of 1822, a similar age range as that of traditional college students (see Dunkel \& Anthis, 2001), as young adults are completing the developmental tasks necessary to resolve who they are (Erikson's identity vs role confusion stage, Erikson, 1963). The desirable outcome of this stage is a sense of oneself as a unique human being with a meaningful role to play in society. Developmental tasks in establishing identity include such things as developing purpose, developing autonomy, and developing mature relationships (Chickering \& Reisser, 1993).

In addition, researchers of leader development are realizing that development into adulthood occurs concurrently with development as a leader (see Bartone, Snook, Forsythe, Lewis, \& Bullis, 2007; Day, Harrison, and Halpin, 2009; McCauley, Drath, Palus, O'Connor, \& Baker, 2006), which makes it likely that psychosocial development during early adulthood is important in the development of a LPS. Sorcher \& Brant (2002), in their leader development practice, assert that "our experience has led us to believe that much of leadership talent is hardwired in people before they reach their early or mid-twenties" (pp. 81). Thus, tying identity development and leader development together, Avolio \& Vogelgesang (2011) in their model assert that adolescence is the key time to focus on leadership development. We expand Avolio and Vogelgesang's model (2011) to include the category of psycho-social development that they assume but do not include. Avolio \& Vogelgesang (2011) assert that it makes sense to begin leadership development before one's actual self is formed, in that individuals often explore LPSs prior to solidifying a leader actual self.

During the college years, developmental scientists believe that young adults seek to resolve the childparent relationship in a search for independence (Erikson, 1963), to establish a sense of identity and selfworth (Chickering \& Reisser, 1993; Erikson, 1968), and to form concepts about themselves as separate adult persons (Chickering \& Reisser, 1993; Kegan, 1982). They also develop increasingly mature patterns of interpersonal behaviors, coping styles, career orientations, values systems, and lifestyles that will greatly influence the shape of their futures (Mayhew et al., 2016). Students who have developed psychosocially are more aware of how they influence other people and conversely how other people influence them (Winston, Miller \& Cooper, 1999). The awareness that they are influencing other people may allow these individuals to see how they could lead others in the future, thus creating a LPS. Based on these arguments we present the following hypothesis:

H3: Level of psycho-social development associated with young adult development (i.e. developmental tasks associated with identity formation) is positively related to scoring higher on a LPS scale. 


\section{Impact on Decision to Participate in Leadership Development During College}

Through the selection and construction of possible selves, individuals can be viewed as producers of their own development (e.g., Kendall, Lerner, \& Craighead, 1984). Self-regulation and discrepancy theories suggest how this process occurs. According to self-regulation theory, a possible self determines which stimuli in their environment trigger their attention, which stimuli are recalled, and what type of inferences they draw from those stimuli (Greenwald \& Pratkanis, 1984; Kihlstrom \& Cantor, 1984). Thus, the possible self becomes a regulator of the individual's behavior. Using discrepancy theory, once a possible self has been developed, students will actively seek opportunities to achieve the goals and desires associated with their possible self to reduce the discrepancy between their actual and possible self. Possible selves have been linked with academic outcomes, delinquent involvement, and health risk behaviors in adolescents (Oyserman \& Fryberg, 2006). In the case of LPSs, students who see leadership available to them through development and have goals to be a leader after college are likely to seek out opportunities to become a leader while in college through such opportunities as participation in leadership development programs or participation in leader roles in clubs and/or organizations. In line with the theory and research on possible selves, Avolio \& Vogelgesang (2011) suggest that holding a LPS is associated with the further development of the leader self-concept by which students participate in activities such as leader positions and developmental opportunities. Based on this reasoning, we are interested in students' decision to participate in leader developmental opportunities and leader position opportunities based on their holding a LPS. This leads to the following hypotheses:

H4a: Students with higher scores on a LPS scale will be more likely to participate in leader development opportunities or leader role opportunities than students with lower scores on a LPS scale.

\section{METHODS}

We tested hypotheses using identical or similar measures on 3 college student populations using secondary databases, comparing: 1.) first semester college freshmen participating in a leadership learning community (LLC) with first semester college freshmen not participating at a single university; 2.) upperclassmen who held or had held at least one on-campus leadership position to upperclassmen who had never held an on campus leadership position at a single university; and 3.) in a longitudinal study of 4 additional schools (not including the single university in the first two samples), students who participated in leadership development program freshmen year and continued with their leadership development their second year (one set of analysis) and their third year (another set of analyses). We describe the measures in the first study. In the subsequent studies, we describe any differences in the measures.

\section{Study 1: Freshman at a University}

\section{Participants}

Participants were recruited in two ways. First, researchers approached administrators in charge of a LLC at a large Master's university on the east coast to elicit participation from students involved in the program. The LLC is a living/learning community that focuses on leadership development and community service and is open to any first-year student. The students take leadership coursework during their first fall semester and participate in weekly service-learning projects that coincide with material learned in their leadership course. Additionally, they participate in leadership seminars, retreats, and conferences throughout the year that students outside of the program would not engage in. 82 of the 274 first-semester students enrolled in the LLC completed $90 \%$ or more of the survey for a $30 \%$ response rate. Secondly, freshmen not participating in the LLC were recruited through subject pool recruitment systems as a requirement for certain psychology courses. 131 of 611 freshmen enrolled in these courses completed the survey for a response rate of $21 \%$. Students were traditionally-aged (18-24 years old) freshmen with $68 \%$ female, $42 \%$ were White, 15\% African-American, 33\% Hispanic, 5\% Asian, and 5\% Other. 


\section{Procedures}

A graduate student elicited student participation through an in-person plea to freshmen students participating in the LLC. If a student indicated interest, they were emailed a link to an on-line survey. For those not participating in the LLC, the study was posted on the school's subject pool recruitment platform. Students completed the survey at a time and location of their choosing; the survey took approximately one hour to complete. Students who successfully completed $90 \%$ of the survey received a $\$ 10$ gift card (LLC) or class credit (psychology).

\section{Measures}

Genetic factors were measured using self-reported high school GPA.

Situational factors focused on three areas: Family background, presence of a peer role model or adult mentor, and past leadership experiences and triggering event. Family background was measured using an item measuring student perception of SES: "How would you describe your family's financial situation?" Response categories included "Well below average", "Somewhat below average", "Above average", "Somewhat above average", and "Well above average". Presence of a peer role model or adult mentor was measured with two questions asking whether students had adult and peer mentors or role models. Response categories for these questions were "Yes" and "No". Past leadership experience was assessed on the following: 1.) experience in leader roles during high school, 2.) duration in leadership situations in high school and 3) perception of overall leadership experience as compared to peers. Items were collapsed into one scale measuring students' overall past leadership experience $(\alpha=.78)$. Triggering event was measured by asking "Can you recall an incident or conversation that encouraged you to develop leadership skills?" Response categories were "Yes" and "No".

Psychosocial Development was measured using two scales from the Student Developmental Task and Lifestyle Assessment (SDTLA, Winston, Miller \& Cooper, 1999), which assesses the development of college students based on various psychosocial development models. In this study, we used the following scales: Autonomy which measures both instrumental, social, and emotional independence. As sample item is "I satisfactorily accomplish all important daily tasks (e.g., class assignments, test preparation, room/apartment cleaning, eating, and sleeping)." and Mature Interpersonal Relationships, which measures whether students are shifting towards greater trust, independence, and individuality. A sample item is" When" I wish to be alone, I have difficulty communicating my desire to others in a way that doesn't hurt their feelings (R)." Since the investigation is concerned with psychosocial development as a global construct, we combined the subscales into a single scale (Cronbach's alpha $=.82$ ).

LPS: A formative 10-item LPS scale was developed using existing items in the databases to determine if students thought of leadership as something that they could develop and whether they wanted to develop it within themselves. Formative measures are commonly used for constructs conceived as composites of specific component variables (Hauser \& Goldberger, 1971; Marsden, 1982). The measure includes 5 items that determine whether an individual sees leadership as something that is innate or that it can be developed over time (Perceived control dimension of LPS). The items were "Leadership is something that a person possesses inside themselves, similar to the way one is born intelligent or wit;" "Only leaders do leadership;" "Leadership occurs when one or a few people in a group or community hold more power than others;" "Leaders have skills or characteristics that followers do not;" and "Under most circumstances, only one person can be the leader at a time (Reverse scored; Cronbach's Alpha = .69). This scale also included 5 items intended to measure an individual's goals in becoming a leader (Accessibility dimension). These items were "My main goal professionally is to achieve a leadership position in my field of study;" "I have plans to develop myself as a leader during college to achieve my professional goals after college;" "I had planned to be in a leader position when I entered college;" "I do not see myself in charge of others in my future (negatively scored);" "I see myself continuously furthering or advancing in the development of my leadership throughout my life." (Cronbach's alpha=.76). Response categories for both included "Strongly disagree", "Disagree", "Neither disagree nor agree", "Agree", and "Strongly agree" 
Leadership Development Participation. Students were divided into two groups based on whether they participated in the LLC. Freshmen who participated in the LLC their first semester were labeled as participating in leadership development. Freshmen not participating in the LLC first semester were labeled as not participating in leadership development.

\section{Results}

Scale descriptives and correlations are provided in Table 1. To test hypotheses $1,2(a, b$, and c), and 3, a linear regression was conducted in which GPA (H1), SES (H2a), role model and mentor (H2b), previous leadership experiences and triggering event (H2c) and SDTLA scales (H3) were regressed on the LPS scale $\left(\mathrm{R}^{2}=.184, \mathrm{p}<.000\right)$. See Table 2 .

TABLE 1

STUDY 1: MEANS, STANDARD DEVIATIONS, AND CORRELATIONS

\begin{tabular}{|c|c|c|c|c|c|c|c|c|c|c|c|}
\hline Variable & Mean & S.D. & 1 & 2 & 3 & 4 & 5 & 6 & 7 & 8 & 9 \\
\hline LPS & 3.26 & 0.62 & & & & & & & & & \\
\hline HS GPA & 3.32 & 0.37 & -.052 & & & & & & & & \\
\hline $\begin{array}{l}\text { SES } \\
\text { Peer Role }\end{array}$ & 2.77 & 0.89 & -.38 & .088 & & & & & & & \\
\hline Model & 0.53 & 0.5 & $.169 *$ & $-.149 *$ & -.083 & & & & & & \\
\hline Adult Mentor & 0.7 & 0.46 & $.193 * *$ & -.112 & -.062 & $.435 * *$ & & & & & \\
\hline $\begin{array}{l}\text { Past Leadership } \\
\text { Triggering }\end{array}$ & 2.69 & 0.86 & $.140^{*}$ & .125 & .128 & $.180 * *$ & $.249^{* *}$ & & & & \\
\hline Event & 0.63 & 0.49 & $.246^{* *}$ & -.101 & .015 & $.422 * *$ & $.446 * *$ & $.255^{* *}$ & & & \\
\hline $\begin{array}{l}\text { SDTLA } \\
\text { Leadership }\end{array}$ & 3.31 & 0.87 & $.207 * *$ & .031 & -.028 & $.183^{*}$ & .124 & $.191 *$ & $.260 * *$ & & \\
\hline $\begin{array}{l}\text { Development } \\
\text { Participation }\end{array}$ & 0.39 & 0.49 & $.162 *$ & $-.254 * *$ & -.109 & $.421 * *$ & $.249 * *$ & $.225^{* *}$ & $.297 * *$ & $.193 *$ & \\
\hline
\end{tabular}

Note. $N=213$.

${ }^{*} p<.05 .{ }^{* *} p<.01$

TABLE 2

STUDY 1: LINEAR REGRESSION PREDICTING LPS

\begin{tabular}{lcc}
\hline \multicolumn{1}{c}{ Variables } & $B$ & SE \\
\hline HS GPA & .037 & .141 \\
SES & -.011 & .054 \\
Peer Role Model & -.019 & .109 \\
Adult Mentor & .063 & .115 \\
Past Leadership & .011 & .056 \\
Triggering Event & $.372^{* * *}$ & .123 \\
SDTLA & $.193 *$ & .074 \\
$\mathrm{R}^{2}$ & $.184 * * * *$ \\
\hline Note. $N=213$. \\
$* p<.05, * * p<.01, * * * p<.005$
\end{tabular}




\section{Hypothesis 1}

The effect of GPA on LPS was not significant providing no support for Hypothesis 1, students with a higher GPA did not show a higher score on the LPS scale.

\section{Hypotheses $2 a, 2 b$, and $2 c$}

These assessed whether the situational factors of family SES, having a role model and mentor, previous experience and a triggering event would contribute to one's LPS. Only triggering event significantly predicted the measure of LPS $(B=.372, p<.005)$. These results do not support Hypotheses $2 \mathrm{a}$ and $2 \mathrm{~b}$, which hypothesize that higher family SES and having a role-model or mentor would be associated with a higher score on the LPS. Analyses provide support for Hypothesis $2 \mathrm{c}$ in finding that a triggering event predicted a higher LPS score. These results provide partial support for the premise that previous leadership experiences influence the development of a LPS.

\section{Hypothesis 3}

This assessed the hypothesis that developmental factors contribute to one's LPS. This hypothesis was supported. Students with higher scores on the SDTLA were more likely to have higher scores on the LPS scale $(B=.193, p<.05)$.

\section{Hypothesis 4}

This was tested by conducting a bivariate logistical regression assessing whether holding a higher LPS would lead to increased leader development participation. This analysis was statistically significant $\left(\chi^{2}=5.23, p<.05, \mathrm{df}=1\right)$ providing support for the hypothesis that those who have a higher LPS score are more likely to participate in a freshman LLC. See Table 3.

TABLE 3

\section{STUDY 1: LOGISTIC REGRESSION PREDICTING CONTINUED LEADERSHIP DEVELOPMENT PARTICIPATION}

\begin{tabular}{lll}
\hline & $B$ & SE \\
\hline LPS & $.553^{*}$ & .246 \\
$\chi 2$ & $5.23^{*}$ & \\
\hline $\begin{array}{l}\text { Note. } N=213 . \\
* p<.05\end{array}$ & & \\
\end{tabular}

Study 1, which utilized a sample of 213 freshmen from a single university indicate partial support for the first half of the modified Avolio and Vogelgesang's (2011) model with situation (triggering event) and psychosocial development but not genetic factors contributing to LPS. Those who hold a higher LPS are, in turn, more likely to engage in leader development participation during college. Next, we tested these same hypotheses on upperclassmen in a single university.

\section{Study 2: Upperclassmen at a University}

\section{Participants}

Participants were recruited in three ways for this study from the same university as above. First, students in their third and fourth year of college were recruited through subject pool recruitment systems as a requirement for certain psychology courses $(N=91)$. Second, additional upperclassmen were recruited through the co-curricular leadership development office on campus $(N=56)$. Lastly, upperclassmen Resident Assistants (RAs) were invited to participate through the RA director $(N=21)$ at the school. Total participants equal $168.72 \%$ of all participants were female, $51 \%$ Caucasian, $27 \%$ Hispanic, 9\% Asian, and 7\% Black. Students were under the age of 24, with a majority (76\%) being 20 21. 


\section{Procedure}

All students were invited to participate by either completing the survey at a certain time and location or by responding to an email link to fill out an on-line survey. Students received class credit or leadership credit for their participation (completing at least $90 \%$ of the survey).

\section{Measures}

All measures were the same except the following: For Situational factors: past leadership experience in high school was not collected. Leadership Development Participation: students were asked to indicate what leadership positions they held during college. Leadership positions included elected roles in organizations such as president and vice president, along with the other roles that the university defines as leadership such as RAs, Student Ambassador, and office managers. Students were then divided into two groups based on their responses. Students who currently or previously held a leadership position were placed into the leadership group $(N=106)$. Students who did not hold a leadership position at any time in their college career were classified as non-leaders $(N=62)$.

\section{Results}

Scale descriptives and correlations are provided in Table 4. To test hypotheses 1, 2(a, b, and c), and 3, a linear regression was conducted in which GPA (H1), SES (H2a), role model and mentor (H2b), triggering event $(\mathrm{H} 2 \mathrm{c})$, and SDTLA scales $(\mathrm{H} 3)$ were regressed on the LPS variable $\left(R^{2}=.489, p<.000\right)$. See Table 5.

TABLE 4

STUDY 2: MEANS, STANDARD DEVIATIONS, AND CORRELATIONS

\begin{tabular}{lcccccccccc}
\hline Variable & Mean & S.D. & 1 & 2 & 3 & 4 & 5 & 6 & 7 & 8 \\
\hline LPS & 3.35 & .36 & & & & & & & & \\
HS GPA & 3.36 & .45 & -.063 & & & & & & \\
SES & 2.91 & .91 & $-.168^{*}$ & -.043 & & & & & \\
Peer Role Model & .39 & .49 & .040 & .076 & .025 & & & & \\
Adult Mentor & .60 & .46 & $.215^{* *}$ & .020 & .040 & $.24^{* *}$ & & & \\
Triggering Event & .45 & .50 & $.267^{* *}$ & -.036 & .063 & $.21^{* *}$ & $.253^{* *}$ & & & \\
SDTLA & 3.46 & .46 & $.416^{* *}$ & .092 & -.007 & .096 & $.251^{* *}$ & $.261^{* *}$ & & \\
Leader & & & & & & & & & \\
Development & & & & & & & & & \\
Participation & .39 & .43 & .161 & .126 & -.066 & $.177^{*}$ & .143 & -.008 & $.259^{* *}$ \\
\hline
\end{tabular}

Note. $N=168$.

${ }^{*} p<.05 .{ }^{* *} p<.01$ 


\section{STUDY 2: LINEAR REGRESSION PREDICTING LPS}

\begin{tabular}{lcc}
\hline Variables & $B$ & SE \\
\hline HS GPA & .026 & .058 \\
SES & $-.061^{*}$ & .028 \\
Peer Role Model & -.049 & .055 \\
Adult Mentor & .058 & .056 \\
Triggering Event & $.129 *$ & .055 \\
SDTLA & $.120^{* * * *}$ & .060 \\
$\mathrm{R}^{2}$ & $.489 * * * *$ & \\
\hline
\end{tabular}

Note. $N=168$.

$* p<.05, * * p<.01, * * * p<.005, * * * * p<.001$

\section{Hypothesis 1}

The effect of GPA on LPS was not significant, providing no support for Hypothesis 1.

\section{Hypothesis $2 a, 2 b$, and $2 c$}

These assessed whether situational factors of family SES, having a role model and mentor, and a triggering event would contribute to one's LPS. Analyses provide support for hypothesis $2 \mathrm{c}$, that a triggering event would predict a higher LPS score was supported $(B=.129, p<.05)$. Results were opposite of that predicted in hypothesis $2 \mathrm{a}$, as we found that higher family SES significantly and negatively predicted the measure of LPS $(B=-.061, p<.05)$. Results did not support hypothesis $2 b$, which predicted that having a role-model or mentor would increase the chances of having a higher score on the LPS scale. These results provide partial support for the notion that previous situational factors influence the development of a LPS.

\section{Hypothesis 3}

This assessed the contribution of developmental factors that contribute to one's LPS. This hypothesis was supported. Students with higher scores on the SDTLA were more likely to have higher scores on the LPS scale $(B=.274, p<.001)$.

\section{Hypothesis 4}

This hypothesis was tested by conducting a bivariate logistical regression assessing whether holding high LPS would lead to leader development participation. This analysis was statistically significant $\left(\chi^{2}=\right.$ 8.88, $p<.003, \mathrm{df}=1)(B=1.38 p<.005)$, providing support for the hypothesis that those who have a higher score on LPS are more likely to take on leader roles in college.

Study 2, which utilized a sample of 168 upperclassmen, found support for the first half of the modified Avolio and Vogelgesang's (2011) model with situation (triggering event) and psycho-social development but not genetic factors contributing to LPS. In addition, opposite of that predicted by the model, SES was negatively associated with LPS. It was found that those who hold a higher LPS are, in turn, more likely to engage in leader roles during college. Next, we tested hypotheses using a longitudinal sample based on 4 additional schools. 


\section{Study 3: Longitudinal: Freshman, Sophomore, and Junior Years}

\section{Participants}

Researchers approached administrators in charge of freshman leader development programs to elicit participation from four schools offering a freshman leadership development experience and both curricular and co-curricular leadership development programs. Those administrators reached out to students participating in the freshmen leadership development program to alert them to the study, describe it, and encourage their participation. 358 of the 1,546 first-semester students enrolled in freshman leader development programs at these schools completed $90 \%$ or more of the survey participated (24\% response rate). Students were traditionally-aged freshmen with 64\% female, 53\% Caucasian, 7\% AfricanAmerican, 11\% Hispanic, and 20\% Asian. The students who participated their freshmen year were surveyed again their sophomore and junior years. 208 of the 358 students completed the Time 2 sophomore year survey (for a response rate of 58\%). Thus far, 84 of the 164 students who completed their junior year have completed the Time 3 junior year survey (for a response rate of $51 \%$ ).

\section{Procedures}

A graduate student sent emails to interested students with a link to an online survey. Students who completed the first survey were contacted via email again during their sophomore year to complete a second survey. Students who had reached their junior year at the time of this data analysis were contacted via email to complete a third survey. Students received a $\$ 10$ gift card for their participation in each survey (and completing at least $90 \%$ of the survey).

\section{Measures}

All measures were the same as Study 1, and collected during the freshman year, except the following:

\section{Leadership Development Experience Participation: Sophomores}

Students were divided into two groups: those who continued to participate in leadership development after the first-year leadership development program and those that did not. During the spring semester of their second year, students were asked questions pertaining to their involvement in programs, clubs, organizations and sports teams during their first two years of college. Students who continued to hold a leadership position were placed into the leadership development experience group. Leadership positions included elected roles in organizations such as president and vice president, along with the other roles that the university defines as leadership such as resident assistant, student ambassador, and office manager. Additionally, students who were participating in leadership development specific (co-curricular) programs or completing an academic leadership program were also placed in the leadership development experience group $(N=135)$. Students who did not participate in any of the above were placed in the discontinued leadership development post freshman year group $(N=71)$.

\section{Leadership Development Experience Participation, Juniors}

This was similar to the above except that students were asked about their involvement in leader roles and leadership development programs during their three years of college. Students were divided into two groups: those who continued to participate in leadership development $(N=62)$ and those that $\operatorname{did} \operatorname{not}(N=$ $35)$.

\section{Results}

Scale descriptives and correlations are provided in Table 6 . To test hypotheses $1,2(a, b$, and c), and 3 using students' freshmen data, a linear regression was conducted in which GPA (H1), SES (H2a), Role models/mentors $(\mathrm{H} 2 \mathrm{~b})$, previous leadership experiences and triggering event (H2c), and SDTLA (H3) scales were regressed on the LPS variable. A significant regression equation was found $\left(R^{2}=.347, p<\right.$ $.000)$. See Table 7. 
TABLE 6

STUDY 3: MEANS, STANDARD DEVIATIONS AND CORRELATIONS

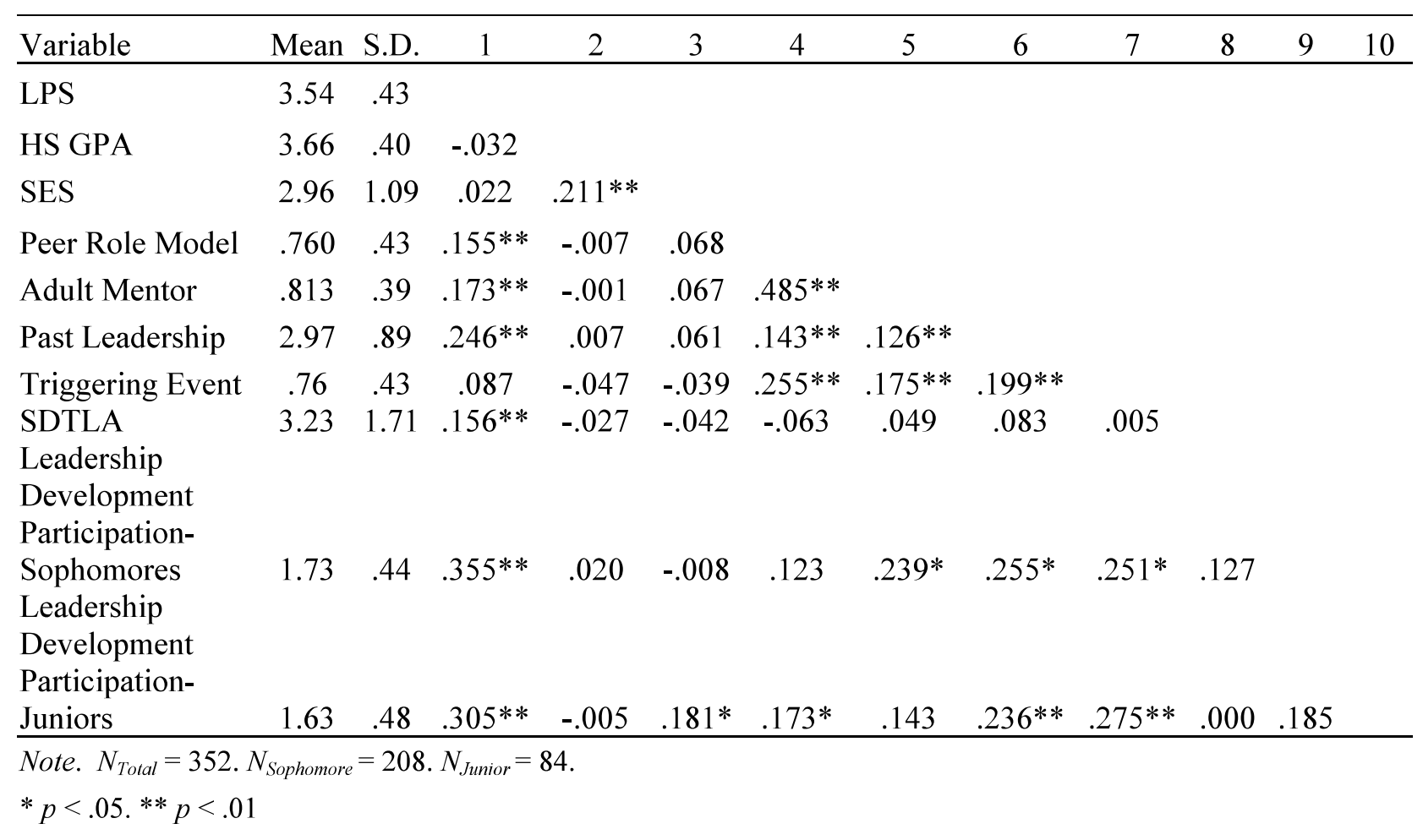

TABLE 7

STUDY 3: LINEAR REGRESSION PREDICTING LPS

\begin{tabular}{lll}
\hline Variables & $B$ & SE \\
\hline HS GPA & -.012 & .070 \\
SES & -.002 & .022 \\
Peer Role Model & .091 & .064 \\
Adult Mentor & .113 & .069 \\
Past Leadership & $.088^{* * *}$ & .027 \\
Triggering Event & -.005 & .061 \\
SDTLA & $.059 * * *$ & .017 \\
$\mathrm{R}^{2}$ & $.121^{* * * *}$ & \\
\hline
\end{tabular}

Note. $N=352$.

${ }^{*} p<.05,{ }^{* *} p<.01,{ }^{* * *} p<.005,{ }^{* * * *} p<.001$ 


\section{Hypothesis 1}

The effect of GPA on LPS was not significant, providing no support for Hypothesis 1.

\section{Hypothesis $2 a, 2 b$, and $2 c$}

These assessed whether situational factors such as family SES, having a role model and mentor, previous leadership experience and a triggering event would contribute to one's LPS. Only past leadership experience significantly predicted LPS $(B=.088, p<.005)$. These results do not support Hypothesis $2 \mathrm{a}$, or $2 \mathrm{~b}$, which hypothesized that higher family SES and having a role model and mentor would be associated with a higher score on the LPS. Analyses provide support for Hypothesis $2 \mathrm{c}$ in finding that past leadership experience predicted a higher LPS score. Cumulatively, these results provide partial support for the premise that situational factors influence the development of a LPS.

\section{Hypothesis 3}

This hypothesis assessed the contribution of developmental factors that contribute to one's LPS. This hypothesis was supported. Students with higher scores on the SDTLA were more likely to have higher scores on the LPS scale $(B=.059, p<.005)$.

\section{Hypothesis 4}

This hypothesis was tested on sophomores and juniors by conducting two bivariate logistical regressions assessing whether holding a higher LPS would lead to increased leader development participation. Using the sophomore year data, this analysis was statistically significant $\left(\chi^{2}=29.59, p<\right.$ $.001, \mathrm{df}=1)(B=2.3 p<.001)$ providing support for Hypothesis 4 , that sophomores who had a higher LPS score their freshman year were more likely to engage in leadership participation through their sophomore year. Using junior year data, this analysis was statistically significant $\left(\chi^{2}=11.76, p<.001\right.$, $\mathrm{df}$ $=1)(B=2.24, p<.005)$ again providing support for Hypothesis 4 , that juniors who had a higher LPS score their freshmen year were more likely to engage in leadership development participation through their junior year. See Table 8 .

TABLE 8

\section{STUDY 3: LOGISTIC REGRESSION PREDICTING CONTINUED PARTICIPATION IN} LEADERSHIP DEVELOPMENT SOPHOMORE AND JUNIOR YEARS

\begin{tabular}{lllll}
\hline & Sophomores & \multicolumn{3}{l}{ Juniors } \\
\hline & $B$ & SE & $B$ & SE \\
\hline LPS & $2.3^{* * * *}$ & .473 & $2.24^{* * *}$ & .72 \\
& & & & $11.76^{* * * * *}$ \\
$\chi^{2}$ & $29.59^{* * * *}$ & & & \\
\hline
\end{tabular}

Note. $N=208$.

${ }^{*} p<.05,{ }^{* *} p<.01,{ }^{* * *} p<.005,{ }^{* * * *} p<.001$

Study 3, which utilized a longitudinal sample of 352 undergraduate students from 4 different universities, found partial support for the first half of the modified Avolio and Vogelgesang's (2011) model with situation (past leadership experience) and psycho-social development but not genetic factors contributing to LPS. Those who hold a higher LPS during their freshman year are, in turn, more likely to engage in leader developmental participation during their sophomore and junior years.

While our LPS measure was limited by the fact that our research relied on secondary databases, our findings support strong internal consistency for this formative measure of LPS $(\alpha=.78, .70, .79)$ across all three studies. In addition, given the antecedents and consequences hypothesized by Avolio and Vogelgesang's model related to LPS as predicted, we also conclude support for the nomological network 
of the measure across all three studies. Looking at the correlational analyses (Tables 1, 4, and 7), situational factors including peer role models (Studies 1 and 3), and adult mentors (all three studies), past leadership experience (Studies 1 and 3, not measured in Study 2), and triggering events (Studies 1 and 2) were correlated with LPS when not controlling for other variables. LPS significantly predicted continued leadership development in linear regressions in all three studies. These findings provide support that the initial measure of LPS had construct validity.

To summarize all 3 studies, we found partial support for the first half of the modified Avolio and Vogelgesang's (2011) model with situation (triggering events and past leadership experience) and psycho-social development but not genetic factors contributing to a LPS in all three studies. In the upperclass student study, we found that SES was opposite to that predicted by the model. In addition, support was found for the second half of the model. LPS predicted participation in a freshmen leadership development program, participation in leader roles in upperclassmen, and continued participation in leader development after the freshman year in a longitudinal sample.

\section{DISCUSSION}

The purpose of this research was to delineate the construct of LPS, develop an initial measure of the construct, then explore possible predictors of LPS in college students and assess whether LPS is associated with participation in leadership development or leader roles while in college using Avolio \& Vogelgesang's (2011) model as a guide. We compared freshmen at a single university who participated in a first semester LLC with those who did not; upperclassmen in a single university who participated in leader roles with those who did not; and using longitudinal measures at four universities students who participated in a freshmen leader development program over three years verses those who stopped participating. The variables measured in these databases support the idea that LPS is worthy of study in a college student sample.

Our measure of LPS included two of the four dimensions of possible selves discussed by Norman and Aron (2002). Our findings demonstrated internal consistency as well as construct validity in the sense that the antecedents and consequences of LPS were consistent with Avolio \& Vogelgesang (2011) model. Future research should develop the other facets of LPS beyond the Accessibility and the Perceived Control dimensions though these dimensions can be more difficult to measure. In addition, future studies should include discriminant and concurrent validity assessment of the LPS measure.

While we found partial support for the idea that prior experience and psycho-social development have an impact on LPS in all three studies, we did not find support for a genetic component on the development of an LPS in any of the studies. And in one study, we found that, opposite of what was predicted by the model, SES was negatively associated with LPS. We also found support for the idea that holding an LPS is associated with participation in leadership development activities in college in all three studies. Evidence from our studies suggest that LPS should be considered and included as a predictor of leadership development activities in college students and may help us further understand the development of a leader identity.

\section{Theoretical Implications}

Although theory on possible selves does not include a genetic component, Avolio and Vogelgesang (2011) hypothesized a relationship between genetics and holding a LPS. They based this prediction on leadership research demonstrating that there is a connection between genetic variables such as intelligence, cognitive ability, and personality with leader emergence and leader styles (see Arvey, et al., 2014). We did not find support for this relationship using a single self-reported item of high school GPA as a proxy for intelligence (see Kranzler, et al., 2015). However, to more clearly determine whether and what the relationship is between genetics and LPS, future studies using more measures and a twin-based or similar methodology should be conducted.

The possible selves literature suggests that experiences, interpersonal contexts, social norms and social forces, and culture impact the emergence of possible selves. Avolio and Vogelgesang (2011) focus 
specifically on experiences and interpersonal contexts based on families. We included prior experience (prior leadership experience and triggering events) and interpersonal contexts of family and significant others. We found no support for a relationship between family background, based on a single SES item, and the emergence of an LPS. In one of the studies, college upperclassmen who come from families with a lower SES were more likely to hold a higher LPS. This differs from the possible selves literature that found a relationship between SES and work possible self (Pisarik \& Shoffner, 2009) as well as research demonstrating a relationship between SES and likelihood of holding a leader position in college (Soria, et al., 2014). The finding in our study may be due to the particular school context. Future studies might go beyond SES and explore parenting style and whether parents actively encourage students to develop their leadership to more fully understand the relationship between family and the development of a LPS.

We found no support for the idea that having mentors and role models impacted LPS, despite previous evidence that college students do commit to a new possible self when this is validated by a significant other (Carroll, 2014), and do learn leadership or take on a leader identity vicariously from role models and mentors (Ibarra, et al., 2008; Komives, et al., 2005). Future studies need to explore the relationship between mentors and role models and the development of a LPS in more depth. We asked students to indicate whether they had role models and mentors. Future research should investigate the strength of the mentor/role model relationship, whether these role models and mentors encourage the students to think of themselves as leaders (as opposed to doctors, soccer players, or rock stars) and encourage them to develop as such, and whether students see these role models and mentors as leaders to emulate.

We found that both previous leadership experience (in the longitudinal study) and triggering events (freshmen and upperclassmen) impact the emergence of a LPS. This is in line with previous research suggesting that college student pre-college leadership capacity, knowledge, and success regularly emerge as significant predictors of taking on leader positional roles in college and beyond (Arvey, et al., 2007; Dugan, et al., 2008; Dugan \& Komives, 2006). Similarly, triggering events have been linked to leader identity development (Toor \& Ofori, 2008) and leader development (see Shamir \& Eilam, 2005).

As it is hypothesized by the possible selves literature that social norms and social forces impact the development of possible selves, we investigated whether developmental factors, specifically psychosocial development, influenced the presence of a LPS. Identity researchers (see Dunkel \& Anthis, 2001), leadership development researchers (see Bartone, et al., 2007, Day, et al., 2009, McCauley, et al., 2006), and leader development practitioners (see Sorcher \& Brant, 2002) all suggest that late adolescence and early adulthood is a key time to inculcate individuals with a leader possible self. In this study, we included scales associated with psycho-social identity development in terms of establishing autonomy and mature peer relationships. We found relationships between psychosocial development and LPS scores across all three samples. Future research may want to address psycho-social development more broadly and other identity related constructs as suggested by Chickering and Reisser (1993). Other developmental aspects, such as constructive development, should be studied as well (see Kegan 1994).

Finally, we found evidence to support the notion hypothesized by Avolio and Vogelgesang (2011) that having a higher LPS score is associated with further development of self as a leader either through participation in leadership developmental activities or ascending into leadership positions. Together these results suggest that leadership development researchers should add the LPS to their models of leader development.

\section{Practical Implications}

All three studies found that students with a more developed LPS are more likely to participate in future leadership development, or take on leader roles, to further develop an individual's leader identity. A more developed leader identity results in taking on leader roles and participation in further leadership development (Day et al., 2009). This cycle suggests that LPS should be cultivated early while students are still in high school or early in college to give them as much time as possible to begin and cultivate their leader identities.

Our research suggests two routes to do this. First, this adds credence to the notion that we should encourage students to get involved in leadership development activities and take on leadership roles while 
in college and also while in high school. These activities should lead to the emergence of a LPS, which in turn should lead to higher rates of involvement in leadership development activities and leader roles while in college and beyond.

Second, suggested by our findings on psycho-social development, developing autonomy and building mature peer relationships with diverse others is an important part of developing a LPS. While college leadership development programs focus on formal leadership theories and the development of competencies, they should also focus on helping students develop autonomy and cultivate meaningful relationships. This could include learning about healthy relationships, time and space to create new friendships, or reflection on current relationships and this may also increase leadership involvement.

\section{Limitations and Future research}

This study used secondary databases from three separate samples. Although we did find promising evidence suggesting it is beneficial to foster students' LPS through leader development, future research is needed to more purposefully develop and validate a LPS scale and test hypotheses more directly. To truly understand the possible relationship between genetics and the LPS, twin study methodologies including a broader set of measures need to be conducted. In addition, there are other leader development motivational variables in the literature which may have relationships to LPS and they should be investigated along-side it. Two examples are leader developmental readiness (LDR) and Leader Self Efficacy (LSE), both of which were included in Avolio \& Vogelgesang's (2011) model, but not tested here. Research should investigate the relationships between LPS, LDR, and LSE and how together they impact pursuit of leader development, ascendance into leader roles, and the emergence of a leader identity.

While there were limitations of our research, this research is the first to attempt to measure LPS and to test Avolio and Vogelgesang's (2011) model on the importance of, and the antecedents and outcomes of a LPS. Future research should attempt to construct and validate LPS scales and further investigate its relationship to other leadership constructs.

\section{ACKNOWLEDGEMENTS}

This research was funded in part by a grant from the C. Charles Jackson Foundation 


\section{REFERENCES}

Arvey, R. D., Wang, N., Song, Z., \& Li, W. (2014). The biology of leadership. The Oxford Handbook of Leadership and Organizations, 73.

Arvey, R. D., Zhang, Z., Avolio, B. J., \& Krueger, R. F. (2007). Developmental and genetic determinants of leadership role occupancy among women. Journal of Applied Psychology, 92(3), 693.

Avolio, B. J., \& Luthans, F. 2006. The high impact leader: Authentic, resilient leadership that gets results and sustains growth. New York: McGraw-Hill.

Avolio, B. J., \& Vogelgesang, G. (2011). Beginnings matter in genuine leadership development. Early development and leadership: Building the next generation of leaders, 179-204.

Bartone, P. T., Snook, S. A., Forsythe, G. B., Lewis, P., \& Bullis, R. C. (2007). Psychosocial development and leader performance of military officer cadets. The Leadership Quarterly, 18(5), 490-504.

Bradley, R. H., \& Corwyn, R. F. (2002). Socioeconomic status and child development. Annual Review of Psychology, 53(1), 371-399.

Carroll, P. J. (2014). Upward self-revision: Constructing possible selves. Basic and Applied Social Psychology, 36(5), 377-385.

Chickering, A. W., \& Reisser, L. (1993). Education and Identity. The Jossey-Bass Higher and Adult Education Series. Jossey-Bass Inc., Publishers, 350 Sansome St., San Francisco, CA 94104.

Daly, M., Egan, M., \& O'Reilly, F. (2015). Childhood general cognitive ability predicts leadership role occupancy across life: Evidence from 17,000 cohort study participants. The Leadership Quarterly, 26(3), 323.

Day, D. V., Harrison, M. M., \& Halpin, S. M. (2009). An integrative approach to leader development: Connecting adult development, identity, and expertise. New York, NY: Routledge.

De Neve, J. E., Mikhaylov, S., Dawes, C. T., Christakis, N. A., \& Fowler, J. H. (2013). Born to lead? A twin design and genetic association study of leadership role occupancy. The Leadership Quarterly, 24(1), 45-60.

Dugan, J. P., \& Komives, S. R. (2006). Select descriptive findings from the multiinstitutional study of leadership. Concepts \& Connections, 15(1), 16-18.

Dugan, \& Komives, S. R. (2010). Influences on college students' capacities for socially responsible leadership. Journal of College Student Development, 51, 525-549.

Dugan, J. P., Garland, J. L., Jacoby, B., \& Gasiorski, A. (2008). Understanding commuter student selfefficacy for leadership: A within-group analysis. NASPA Journal, 45(2), 282-310.

Dunkel, C.S. \& Anthis, K.S. (2001). The role of possible selves in identity formation: A short-term longitudinal study. Journal of Adolescence, 24, 765-776.

Erikson, E. H. (1950). Identity and the life cycle. New York: W.W. Norton \& Co.

Frazier, L. D., \& Hooker, K. (2006). Possible selves in adult development: Linking theory and research. Possible selves: Research and application, 41-59.

Frey, M. C., \& Detterman, D. K. (2004). Scholastic assessment or g? The relationship between the scholastic assessment test and general cognitive ability. Psychological Science, 15(6), 373-378.

Greenwald, A.G., \& Pratkanis, A.R. (1984). The self. In R. S. Wyer \& T. K. Srull (Eds.) Handbook of social cognition. (Vol. 3, pp. 129-178). Hillsdale, NJ: Erlbaum.

Hauser, R. M., \& Goldberger, A. S. (1971). The treatment of unobservable variables in path analysis. Sociological Methodology, 3, 81-117.

Higgins, E. T. (1987). Self-discrepancy: A theory relating self and affect. Psychological Review, 94(3), 319.

Ibarra, H., Snook, S., \& Guillen Ramo, L. (2010). Identity-based leader development. Handbook of Leadership Theory and Practice, 657-678.

Ilies, R., Gerhardt, M. W., \& Le, H. (2004). Individual differences in leadership emergence: Integrating meta-analytic findings and behavioral genetics estimates. International Journal of Selection and Assessment, 12(3), 207-219. 
Judge, T. A., Colbert, A. E., \& Ilies, R. (2004). Intelligence and leadership; A quantitative review and test of theoretical propositions. Journal of Applied Psychology, 89(3), 542-552.

Kan, K. and Tsai, Wei-Der (2005). Parenting practices and children's education outcomes. Economics of Education Review, 24(1), 29-43.

Kegan, R. (1995). In over our heads: The mental demands of modern life. Cambridge, MA: Harvard University Press.

Kendall, P. C., Lerner, R. M., \& Craighead, W. E. (1984). Human development and intervention in childhood psychopathology. Child Development, 71-82.

Kerpelman, J. L., \& Pittman, J. F. (2001). The instability of possible selves: Identity processes within late adolescents' close peer relationships. Journal of Adolescence, 24(4), 491-512.

Kiesner, J., Cadinu, M., Poulin, F., \& Bucci, M. (2002). Group identification in early adolescence: Its relation with peer adjustment and its moderator effect on peer influence. Child Development, 73(1), 196-208.

Kihlstrom, J. F., \& Cantor, N. (1984). Mental representations of the self. Advances in Experimental Social Psychology, 17, 1-47.

Komives, S. R., Owen, J. E., Longerbeam, S. D., Mainella, F. C., \& Osteen, L. (2005). Developing a leadership identity: A grounded theory. Journal of College Student Development, 46(6), 593-611.

Kranzler, J.H, Benson, N. \& Floyd, R.G. (2015). Using estimated factor scores from a bifactor analysis to examine the unique effects of the latent variables measured by the WAIS-IV on academic achievement. Psychological Assessment, 27, 1402-1416.

Lord, R. G., Diefendorff, J. M., Schmidt, A. M., \& Hall, R. J. (2010). Self-regulation at work. Annual Review of Psychology, 61, 543-568.

Maccoby, E. E. (2000). Parenting and its effects on children: On reading and misreading behavior genetics. Annual Review of Psychology, 51(1), 1-27.

Marcus, H., \& Nurius, P. (1986). Possible selves. American Psychologist, 41, 954- 969.

Marsden, P. V. (1982). A note on block variables in multiequation models. Social Science Research, 11, 127-140.

Mayhew, M.J., Rockenbach, A.N., Bowman, N.A., Seifert, T.A., Wolniak, G.C., Pascarella, E.T., \& Terenzini, P.T., (2016). How College Affects Students: $21^{\text {st }}$ Century Evidence that Higher Education Works. Jossey Bass.

McCauley, C. D., Drath, W. H., Palus, C. J., O'Connor, P. M., \& Baker, B. A. (2006). The use of constructive-developmental theory to advance the understanding of leadership. The Leadership Quarterly, 17(6), 634-653.

Mumford, T.V., Campion, M.A., \& Morgeson, F.P. (2007). The leadership skills strataplex: Leadership skill requirements across organizational levels. The Leadership Quarterly, 18, 154-166

Murphy, S. E., \& Johnson, S. K. (2011). The benefits of a long-lens approach to leader development: Understanding the seeds of leadership. The Leadership Quarterly, 22(3), 459-470.

Neville, H. A., \& Cross Jr, W. E. (2017). Racial awakening: Epiphanies and encounters in Black racial identity. Cultural Diversity and Ethnic Minority Psychology, 23(1), 102.

Norman, C. C., \& Aron, A. (2003). Aspects of possible self that predict motivation to achieve or avoid it. Journal of Experimental Social Psychology, 39(5), 500-507.

Oyserman, D., \& Fryberg, S. (2006). The possible selves of diverse adolescents: Content and function across gender, race and national origin. Possible selves: Theory, Research, and Applications, 2(4), 17-39.

Oyserman, D., Bybee, D., \& Terry, K. (2006). Possible selves and academic outcomes: How and when possible selves impel action. Journal of Personality and Social Psychology, 91(1), 188.

Pisarik, C. T., \& Shoffner, M. F. (2009). The relationship among work possible selves, socioeconomic position, and the psychological well-being of individuals in early adulthood. Journal of Career Development, 35(3), 306-325. 
Ployhart, R. E., \& Holtz, B. C. (2008). The diversity-validity dilemma: Strategies for reducing racioethnic and sex subgroup differences and adverse impact in selection. Personnel Psychology, 61, 153-172.

Rubin, K. H., Bukowski, W. M., \& Parker, J. G. (1998). Peer interactions, relationships, and groups. Handbook of Child Psychology.

Sessa, V.I. (2017). College Student Leadership Development, New York: Routledge.

Shamir, B., \& Eilam, G. (2005). "What's your story?" A life-stories approach to authentic leadership development. The Leadership Quarterly, 16(3), 395-417.

Sorcher, M., \& Brant, J. (2002). Are you picking the right leaders? Harvard Business Review, 80(2), 7887.

Soria, K. M., Hussein, D., \& Vue, C. (2013). Leadership for whom? Socioeconomic factors predicting undergraduate students' positional leadership participation. Journal of Leadership Education, 13(1), 14-30.

Toor, S. U. R., \& Ofori, G. (2008). Leadership versus management: How they are different, and why. Leadership and Management in Engineering, 8(2), 61-71.

Winston, R. B., Miller, T. K., \& Cooper, D. L. (1999). Preliminary technical manual for the student developmental task and lifestyle assessment. Athens, GA: Student Development Associates.

Yunus, K. R. M., \& Dahlan, N. A. (2013). Child-rearing Practices and Socio-economic Status: Possible Implications for Children's Educational Outcomes. Procedia-Social and Behavioral Sciences, 90, 251-259. 